\title{
Mersin Körfezi'nden Yakalanan Apogon queketti Kas Dokusu Metal Seviyelerine Mevsimin Etkisi
}

\author{
Yilmaz Uçar ${ }^{1 *}$ \\ ${ }^{1}$ Ordu Üniversitesi, Fatsa Deniz Bilimleri Fakültesi, Fatsa, Ordu, Türkiye (ORCID: 0000-0002-6770-6652)
}

(İlk Geliş Tarihi 1 Aralık 2019 ve Kabul Tarihi 31 Aralık 2019)

(DOI: 10.31590/ejosat.657647)

ATIF/REFERENCE: Uçar, Y. (2019). Mersin Körfezi'nden Yakalanan Apogon queketti Kas Dokusu Metal Seviyelerine Mevsimin Etkisi. Avrupa Bilim ve Teknoloji Dergisi, (17), 1215-1221.

\section{$\ddot{O} \mathbf{z}$}

Su ürünleri insanlar için besleyici bir besin olmalarının yanısıra içeriklerindeki aşırı metal birikimleri ile de tehlikeli olabilmektedirler. Bu çalışmada Kuzeydoğu Akdeniz'den (Mersin Körfezi) avlanan Apogon queketti türünün metal düzeyleri mevsimsel olarak araştırılmıştır. Ayrıca Apogon queketti tüketiminin tüketici sağlığı açısından olası risklerini öngörebilmek amaciyla haftada 1, 3 ve 7 gün tüketim durumlarında yetişkin ve çocuklarda kapsamlı risk değerlendirme (EWI, THQ, TTHQ, CRi) hesaplamaları yapılmıştır. Bulgular, Türk Gıda Kodeksi ve dünya çapında geçerli olan diğer kodeksler kapsamında değerlendirilmiştir. Çalışma sonunda elde edilen bulgular Mersin Körfezi'nde yakalanan A. queketti türünün macro elementler ve iz elementler açısından besleyici düzeyinin yüksek olduğunu ancak $\mathrm{Cd}$ ve As düzeyleri açısından insan sağlığı için potansiyel toksisite gösterebileceğini ortaya çıkarmıştır. Ayrıca metal düzeylerinin mevsimsel açıdan farklılıklar gösterdiği tespit edilmiştir. Mevcut çalışmada incelenen tüm örneklerde EWI değerleri PTWI değerlerinin altında bulunmuştur. THQ $<1$ (çocuklar için haftada 7 gün tüketildiğinde iAs değeri haricinde) olarak belirlenmiştir. Çocuklarda 3 günlük tüketim neticesinde TTHQ'nun 1'e yakın olması nedeniyle dikkat edilmesi gerekmektedir. Yetişkinlerdeki As elementinin THQ değerinin (0.9051) tehlike limite yakın olması nedeniyle 7 günlük tüketim sonrası TTHQ değeri $>1$ olarak bulunmuştur. $\mathrm{Pb}$ düzeylerinin tüketiciler için kanserojen risk düzeylerinin düşük olduğu tespit edilmiştir. $\mathrm{CRi}_{\mathrm{Cd}}$ değeri 3 ve 7 günlük tüketimlerde çocuklar için riskli olurken yetişkinler için 7 günlük tüketim sonucu risk oluşturmaktadır. $\mathrm{CRi}_{\text {As }}$ değerleri ise yetişkinlerde 1 günlük alım sonrası risk oluşturmazken diğer tüm tespit edilen alım günlerinde her iki grup için risk oluşturduğu gözlenmiştir. Her ne kadar şuan ciddi bir ekonomik değere ve tüketim oranına sahip olmasa da, A.queketti zengin makro ve iz element içeriğine sahiptir. Haftalık tahmini alım oranları açısından yoğun tüketilmedikçe tüketici sağlığına yönelik olumsuz bir etkisi olmayacağı belirlenmiştir. Çalışma sonucu elde edilen bulgular ışı̆̆ında Apogon queketti kas dokusu metal seviyelerinin hayvan veya insan beslenmesi için sağlıklı bir diyet bileşeni olarak kabul edilebileceği sonucuna varılabilir.

Anahtar Kelimeler: Apogon queketti, Mevsim, Risk düzeyleri, Metal, Mersin Körfezi

\section{The Effects of Season on Muscle Tissue Metal Levels of Apogon queketti Caught from Mersin Bay}

\begin{abstract}
In addition to being a nutritious nutrient for human beings, seafood can also be dangerous with excessive metal accumulation. In this study, the metal levels of Apogon queketti species caught in the Northeast Mediterranean (Mersin Bay) were seasonally investigated. Besides, comprehensive risk estimation (EWI, THQ, TTHQ, CR) calculations were performed in adult and children in case of consumption of 1, 3 and 7 days a week in order to determine the possible health risks of $A$. queketti consumption. The findings were evaluated within the scope of Turkish Food Codex and other codexes valid worldwide. At the end of the study, A. queketti muscle was found to have high nutrient levels in terms of macro and trace elements but it could show potential toxicity for human health in terms of $\mathrm{Cd}$ and As levels. In addition, it was found that the metal levels differed in terms of seasonal factors. EWI values in all samples were found to be below the PTWI values. THQ was found as <1 (except for iAs values for children when exposure time 7 days/week). People should be attention the fact that TTHQ is close to 1 as a result of exposure time 3 days/week for children. The THQ value (0.9051) of As element for adults was close to the limit of danger. As the THQ (0.9051) of As element is close to the danger limit, after exposure time 3 days/week for adults, the TTHQ value was found to be $>1$. Pb levels were found to be low carcinogenic risk levels for consumers. $\mathrm{CRi}_{\mathrm{Cd}}$ value is risky for children in 3 and 7 days of intake, while it poses a risk for adults after 7 days of intake.
\end{abstract}

\footnotetext{
* Sorumlu Yazar: Ordu Üniversitesi, Fatsa Deniz Bilimleri Fakültesi, Fatsa, Ordu, Türkiye, ORCID: 0000-0002-6770-6652, yucar@cu.edu.tr
} 
$\mathrm{CRi}_{\mathrm{As}}$ values did not pose any risk for adults after 1 day of intake, but it posed a risk for both groups on all other identified intake days. Although it does not currently have a significant economic value and consumption rate, A.queketti has a rich macro and trace element content. It is determined that it will not have a negative impact on consumer health unless it is consumed intensively in terms of estimated weekly purchase rates. It can be concluded that metal levels of Apogon queketti should be regarded as a healthy diet component for animal or human nutrition.

Keywords: Apogon queketti, Season, Risk levels, Metal, Mersin Bay

\section{Giriş}

Gelişmiş ülkelerde endüstriyel faaliyetler yoğun olmasına rağmen, hükümet kontrolleri oldukça sıkı tutularak metal kontaminasyonlarının insanlar üzerine etkileri azaltılmaya çalışılmaktadır. Ancak genel bir kanı olarak denizler kirliliği kompanse edici bir sistem olarak görülmektedir. Bu durum özellikle denizel ekosistemlerdeki metal kontaminasyonlarını dramatik düzeylere ulaştırmıştır. Metal kirliliğindeki bu yaygınlaşma deniz ekosistemleri ve su ürünlerindeki metal düzeylerine yönelik çalışmaların artışına neden olmuştur.

Doğal habitatlarından toplanan canlıların metal konsantrasyonlarının araştırılması; antropojenik etkilerle ortaya çıkan ekosistem kirliliğinin izlenmesi açısından önem arz etmekle birlikte, su ürünlerinin metal düzeylerinin belirlenmesi ayrıca insan sağlı̆̆ı açısından olası risklerin anlaşılması için de önemli bir göstergedir. Çünkü özelde demersal türler, genelde de tüm denizel türler vücutlarında yararlı elementlerin yanı sıra toksik metallerin de birikimini sağlayabilmektedir. Bu durum tüketici sağlığı açısından risk potansiyeli yaratabilmektedir.

Deniz ekosistemlerinde yaşayan türlerin makro elementleri, iz elementleri ve toksik ağır metal seviyeleri, türlerin yaşadığı ekosistemin inorganik döngüsünün anlaşılmasına katkıda bulunur. Ayrıca, halk sağlığı açısından ticari su ürünlerinde bu metallerin birikimlerinin araştırması önemlidir. Su ürünleri, değerli besleyici bileşenlere sahip olduğundan insan ve hayvan diyetleri için çok önemlidir. Bu önemin giderek artmasıyla birlikte ekonomik değeri olan su ürünlerinin yanı sıra lesepsian türler de giderek önemli hale gelmeye başlamıştır.

Lesepsiyen türler olarak tanımlanan ve Süveyş Kanalı aracılığıla sularımıza giren bu canlılardan Kızıldeniz'de 12 cins ve 54 apogonid türü olduğu bildirilmektedir (Akyol ve Ünal, 2014). Apogon queketti, batı Hint Okyanusu, güney Kızıldeniz ve Arap Denizi, Basra Körfezi ve Hindistan ve Natal, Güney Afrika'dan Mozambik'e kadar yaygındır (Smith, 1965; Golani vd., 2002; Froese ve Pauly, 2014). İlk olarak 2004 yılında Akdeniz Bölgesi'nde (Doğu Akdeniz) Eryılmaz ve Dalyan (2006) tarafından bildirilen Apogon queketti, Hint-Pasifik kökenli kardinal balıklar grubunda yer almaktadır. Bu tür ayrıca, Türkiye'nin Levantine kıyıları İskenderun Körfezi'nden, 20-60 m derinlikte ve Akdeniz'in İsrail kıyılarında 58-63 m derinlikte kaydedilmiştir. Bu lesepsiyen balık türü Mersin Körfezi'nde de görülmeye başlanmıştır.

Demersal bir tür olan Apogon queketti, istilacı türler arasındadır. Bu nedenle, bu lesepsiyen türlerin ekonomiye kazandırılması açısından beslenme potansiyellerinin ortaya çıkarılması gerekmektedir. Tamamlayıcı besin öğeleri olarak da tanımlanan metal seviyelerinin araştırılması hem insan sağlığı hem de su ürünlerinin besin seviyelerinin belirlenmesi için gereklidir. Spesifik olarak demersal canlılar ve genellikle bütün sucul canlılar vücutlarında faydalı elementlerin yanı sıra toksik elementler biriktirebilirler. Bu durum tüketici sağlığı için risk potansiyeli yaratabilir. Bu bağlamda, metal seviyelerini ve tüketiciler için olası riskleri araştıran birçok çalışma vardır. Bununla birlikte, bu çalışmalar genellikle yüksek ticari türlere odaklanmıştır. Bu çalışmada, mevsimsel olarak Apogon queketti kasının metal seviyeleri araştırılmış ve metal seviyelerinin tüketicilere olası bazı riskleri değerlendirilmiştir.

\section{Materyal ve Metot}

\section{1. Örnek Temini ve Metal Analizleri}

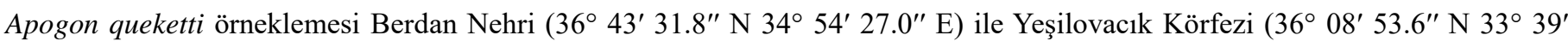
40.7" E) (Şekil 1) arasında ticari balıkçı teknesi kullanılarak yapılmıştır. Örnekleme, 2018 ve 2019 y1llarında dört mevsim olacak şekilde gerçekleştirilmiş ve her bir tür için yeterli miktarda balık numunesi elde edilmiştir. Avlanan örneklerin kas dokularındaki metal içeriklerinin mevsimsel farklılıkları Canlı ve Atlı (2003) tarafından uygulanan yaş yakma yöntemine göre yapılmıştır. Kas dokularındaki metal düzeyleri İndüktif Eşleşmiş Plazma Kütle Spektrometresi (ICP-MS) ile tespit edilmiştir. Çalışmada magnezyum $(\mathrm{Mg})$, fosfor $(\mathrm{P})$, potasyum $(\mathrm{K})$, manganez $(\mathrm{Mn})$, demir $(\mathrm{Fe})$, alüminyum $(\mathrm{Al})$, bakır $(\mathrm{Cu})$, çinko $(\mathrm{Zn})$, selenyum $(\mathrm{Se})$, kadmiyum $(\mathrm{Cd})$, kurşun $(\mathrm{Pb})$ ve arsenik (As) elementleri incelenmiştir. 


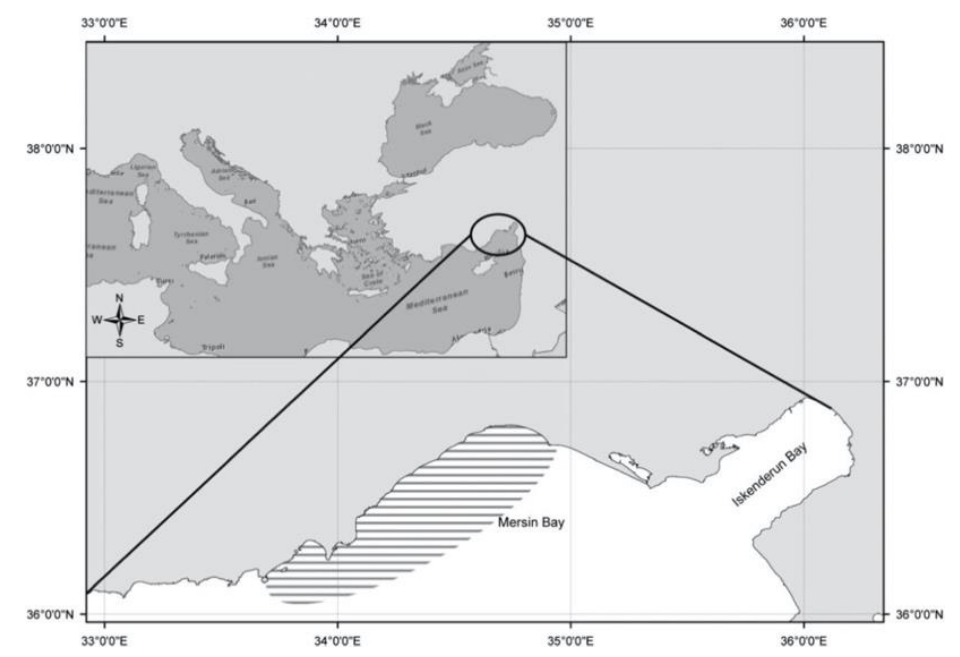

Şekil 1. Örnekleme haritası

Metal analizleri, kuru örnekler üzerinden yapılmıştır. Ancak ICP-MS analizleri sonucunda elde edilen değerler, FAO, Türk Gıda Kodeksi ve $\mathrm{AB}$ tarafından belirlenen limit değerler ile karşılaştırabilmesi ve risk tahmin hesaplamalarının yapılabilmesi amacıyla nem içerikleri doğrultusunda dönüştürülmüştür.

\subsection{Tüketici Sağlığı Risk Değerlendirmeleri}

Kuzeydoğu Akdeniz'de A. queketti türünün tüketiminden kaynaklı olası tüketici risklerini belirlemek amaciyla haftada 1, 3 ve 7 gün tüketimi durumları için tahmini haftalık alım (EWI), hedef tehlike oranı (THQ) ve yaşam boyu kanser riski (CRi) değerleri hesaplanmıştır. Hesaplamalar yetişkin ve çocuk tüketiciler için ayrı ayrı yapılmıştır. Birleşik Devletler Çevre Koruma Ajansı (US EPA, 2000) tarafından bildirilen veriler doğrultusunda yetişkinler ve çocuklar için vücut ağırlıkları ve yaşam süreleri sırasıyla 70 kg70 yıl ve 32 kg-7 yıl (US EPA, 2008) olarak kabul edilmiştir.

As hariç incelenen tüm metallerin ICP-MS analizleri sonucunda elde edilen değerleri doğrudan kullanılmıştır. Ancak As metali için farklı bir dönüşüm faktörü uygulanmıştır. As için risk faktörleri (EWI, THQ ve CR) inorganik arsenik (iAs) için hesaplanırken toksik formun toplam konsantrasyonun \% 3'ü olduğu varsayılarak uygulanmıştır (EFSA, 2009; Andaloro vd., 2012; Copat vd., 2013; Traina vd., 2019).

EWI (Tahmini Haftalık Alım), US EPA (2000) tarafından belirlenen formül kullanılarak hesaplanmıştır.

$E W I=\left(C_{M} \cdot C R\right) / B W$

$\mathrm{C}_{\mathrm{M}}$ : kas dokularındaki metal konsantrasyonu; $\mathrm{CR}$, tüketim oranını (haftada 5, 3 ve 1 gün/kişi tüketim oranları); $\mathrm{BW}$ ise tüketicinin vücut ağırlığını ifade etmektedir. CR değeri, FAOSTAT verileri kullanılarak belirlenmiştir. Buna göre Türkiye'deki balık tüketimi $16.82 \mathrm{~g} /$ kişi/gündür. Çalışmadan elde edilen EWI değerleri WHO/FAO ve EFSA tarafindan belirlenen PTWI (provisional tolerable weekly intake) değerleri ile karşılaştırılmıştır.

THQ, metallerin referans dozu (RfD) ile metallere maruz kalma arasındaki oranın ifadesidir. THQ, metallerin kanserojen olmayan etkilerinin riskini ifade etmek için kullanılır. THQ değeri US EPA $(2014,2019)$ yöntemine göre hesaplanmıştır:

$T H Q=\left[\left(E F . E D . C R . C_{M}\right) /(R f D . B W . A T)\right] .10^{-3}$

EF: maruz kalma sıklığını ifade etmektedir, haftada 1,3 ve 7 günlük tüketim için sırasıyla; yıllık 52, 156 ve 365 gün olarak kullanılmıştır. ED: maruz kalma süresini ifade etmektedir. Yetişkinleri için 70 yıl, çocuklar için 7 yıl olarak kullanılmışıır. RfD, oral referans dozu ifade etmektedir. RfD değerleri US EPA (2019) verilerine göre $\mathrm{Fe}, \mathrm{Cu}, \mathrm{Zn}, \mathrm{Mn}, \mathrm{Se}, \mathrm{Al}, \mathrm{Cr}, \mathrm{As}, \mathrm{Cd}$ ve $\mathrm{Pb}$ elementleri için sırasıyla $0.7,0.04,0.3,0.14,5.10^{-3}, 1.00,3.10^{-3}, 3.10^{-4}, 1.10^{-3}$ ve $4.10^{-3}$ olarak kullanılmıştır. AT, kanserojen olmayan ortalama süreyi ifade etmektedir, AT değeri; 356 gün/yll x ED olarak hesaplanmıştır. CR, CM ve BW bir önceki formülde ifade edilmiştir.

İncelenen tüm elementlerin THQ değerlerinin toplamı ile TTHQ belirlenir.

$\left.T T H Q=T H Q_{A s}+T H Q_{A l}+\ldots+T H Q n\right)$

THQ ve TTHQ değerlerinin $>1$ olması tüketici açısından kanserojen olmayan fakat sağlık problemleri ortaya çıarabilecek olası risklerin olduğunun göstergesidir.

CRi hesaplamaları US EPA (2019)'a göre yapılmıştır. CRi, tüketim yoluyla metal kirliliğine maruz kalan insanlardaki kanser riskinin hesaplanmasında kullanılır. $10^{-5}$ değerinin üzerinde CRi değerleri kanserojen riskinin daha yüksek olduğunun göstergesidir.

$C R i=\left[\left(E F \cdot E D . C R \cdot C_{M} \cdot C s F\right) /(B W \cdot A T)\right] \cdot 10^{-3}$

$\mathrm{CRi}$ hesaplamalarında diğer formüllerden farklı olarak $\mathrm{CsF}$ (cancer slope factor) değeri kullanılmaktadır. CsF değerleri As, $\mathrm{Pb}, \mathrm{Cr}$ ve Cd için sırasıyla $1.5,8.5 .10^{-3}, 0.5$ ve 6.3 (US EPA, 2019) olarak kullanılmıştır.

\section{3. İstatistiksel Analizler}

Veriler, üç tekerrürlü olacak şekilde ortalama ve standart hata olarak hesaplanmıştır. Elde edilen veriler SPSS 15.0 istatistik paket programı kullanılarak varyans analizi (ANOVA) ile değerlendirilmiştir. İstatistiksel farklılıklar $\mathrm{p}<0.05$ önem seviyesinde Duncan testi kullanılarak belirlenmiştir. 


\section{Araştırma Sonuçları ve Tartışma}

\subsection{Balık Kası Metal Düzeyleri}

ICP / MS analizi sonucu dört mevsim boyunca belirlenen Apogon queketti kas dokusunun metal düzeylerinin miktar ilişkileri Tablo 1'de gösterilmiştir. Bu türün kas dokusunda 13 metal belirlenmiş ve değerlendirilmiştir. Apogon queketti türünün metal seviyelerinin mevsime göre değiştiği ve istatistiksel olarak farklılıklar gözlendiği tespit edilmiştir. A. queketti kas dokusundaki metal miktarları $(\mu \mathrm{g} / \mathrm{g}$, ww) maksimumdan minimuma doğru $\mathrm{K}(2364.62-5126.83)>\mathrm{P}$ (1008.50-2142.31)> Mg (152.05-309.45)> Fe (14.19$30.60)>\mathrm{As}(8.74-45.50)>\mathrm{Zn}(6.00-10.53)>\mathrm{Al}(2.79-10.28)>\mathrm{Se}(0.85-1.96)>\mathrm{Pb}(0.60-1.19)>\mathrm{Cu}(0.36-0.64)>\mathrm{Mn}(0.28-0.73)>\mathrm{Cr}$ $(0.28-0.43)>\mathrm{Cd}(0.08-0.12)$ olarak tespit edilmiştir. Tüm metallerin en yüksek seviyeleri Se ve As elementleri haricinde sonbaharda gözlenmiştir. Se için en yüksek değer kış, As için ise yaz mevsiminde gözlenmiştir. Kuzey Doğu Akdeniz'de yapılan farklı metal çalışmalarında da benzer sonuçlar gözlendiği rapor edilmiştir (Ersoy ve Çelik 2010; Yılmaz 2005; Korkmaz vd., 2019).

Arsenik doğada doğal olarak bulunan ve yaygın olarak dağılmış bir elementtir. Genellikle insanlar bu elemente içme suyu ve özellikle deniz ürünleri içeren yiyecekler yiyerek maruz kalmaktadır (Korkmaz vd., 2019). Yüksek bir As dozunun aşılmasının dermatite, düșük nöron transferine ve karaciğer kanserine neden olabileceği bildirilmektedir (Ikem ve Egiebor 2005). Özellikle, toksik metal olarak kabul edilen As, Cd ve Pb, gıdada önemli kirletici maddeler olarak kabul edilir (ATSDR 2017). Bu metallerin gıdada izlenmesi gıda güvenliği ve tüketici sağlı̆̆ için çok önemlidir. FAO/WHO' ya göre maksimum $\mathrm{Cu}, \mathrm{Zn}, \mathrm{Cd}$ ve $\mathrm{Pb}$ içeriği $30,40,0.5$ ve $0.5 \mu \mathrm{g} / \mathrm{g}$; AB'ye göre 10, mevcut değil, 0.1 ve $0.1 \mu \mathrm{g} / \mathrm{g}$ ve Türk Gıda Kodeksine (TGK) göre 20, 50, 0.1 ve $1 \mu \mathrm{g} / \mathrm{g}$ olarak belirlenmiştir. İncelenen türün $\mathrm{Cu}$ içeriği dört mevsim boyunca daha önce belirtilen tüm otoritelerin maksimum limit değerlerinin altında kalmıştır. Bununla birlikte, dört mevsim boyunca, balık kas dokusundaki ortalama Pb seviyeleri otoriteler tarafindan önerilenden daha yüksek olmuştur. Zn miktarı sadece sonbaharda FAO/WHO tarafından önerilen limit değerin üzerinde olurken diğer otoritelerin limit değerlerinin altında kalmıştır. Cd elementi incelendiğinde türün kas dokusundaki miktarı sonbahar dışında diğer mevsimlerde FAO/WHO limit değerinin altında olurken AB ve TGK'nin limit değerlerinden yüksek bulunmuştur.

$\mathrm{Bu}$ çalışmada incelenen türün mevsimler arasında değişken bir element konsantrasyonu olduğu gözlenmiştir. Bu değişkenlik mevsimin gerektirdiği ekolojik ihtiyaçlar, metabolik düzenleme, büyüme, üreme, gıda arzı ve çevresel koşullar, beslenme rejimleri ve davranışları gibi çeşitli faktörlerin birlikte etkileşimini göstermektedir (Brown ve Depledge, 1998; Monikh vd., 2013; Kulcu vd., 2014; Traina vd., 2019).

\subsection{Tüketici Sağlığı Risk Değerlendirmeleri}

Apogon queketti tüketimi sonucu insan sağlığı açısından tahmini riskler EWI (Tablo 2), THQ ve TTHQ (Tablo 3), ve CRi (Tablo 4) olarak hesaplanmıştır. Tahminler, türün yetişkin ve çocuk tüketicilerin öğünlerinde haftada 1,3 ya da 7 gün olması doğrultusunda yapılmıştır. EWI değerleri PTWI değerleri ile karşılaştırılmıştır. Cu, Fe, Zn (FAO/WHO, 1983), Al (JECFA, 2011) ve As (EFSA, 2009) elementleri için otoriteler tarafından belirlenen PTWI değerleri sırasıyla 125, 5600, 300-1000, 2000 ve 15 $(\mu \mathrm{g} / \mathrm{kg} / \mathrm{gün})$ şeklinde bildirilmiştir. Cd tolere edilebilir tüketim değeri, Birleşmiş Milletler Gıda ve Tarım Örgütü FAO ve Dünya Sağlık Örgütü WHO'nun Gıda Katkıları Ortak Uzman Komitesi (JECFA, 2013) tarafından $6.25 \mu \mathrm{g} / \mathrm{kg}$ vücut ağırlığı (BW) aylık olarak değiştirilmiştir. Ancak yeni değer PTMI (provisional tolerable monthly intake) olarak güncellendiği için, mevcut çalışmada PTMI'den PTWI dönüşümü yapılmış ve yaklaşık olarak $6.25 \mu \mathrm{g} / \mathrm{kg}$ BW weekly olarak kullanılmıştır. Mevcut çalışmada incelenen tüm örneklerde EWI değerleri PTWI değerlerinin altında bulunmuştur. Ayrıca balık tüketiminde bu metallerin PTWI açısından herhangi bir risk oluşturmadı̆̆ belirlenmiştir.

THQ, metal kontaminasyonuna maruz kalan tüketicilerin sağlık riskleri açısından doğrudan kesin bir değer vermese de potansiyel tehlikenin belirlenmesi için kullanışlı bir göstergedir. THQ değerinin $>1$ olması; alınan metal düzeyinin $\geq$ oral referans doz (RfD) olduğunu göstermektedir. Bu durum metal tüketiminin tüketici açısından risk teşkil ettiğini ortaya koymaktadır. İncelenen balık türünün kas dokusundaki metal düzeyleri kullanılarak hesaplanan THQ düzeyleri içerisinde en yüksek değer As elementinde tespit edilmiş, diğer tüm metallerde THQ değerlerinin tamamı tehlikeli eşikten $(<1)$ küçük olmuştur. As elementinin THQ değeri (1.9799), haftalık 7 gün tüketimde çocuklarda limit değerin üzerinde bulunmuştur. As değerinin yüksek olmasından dolayı, A. queketti TTHQ değeri çocuk tüketicilerde 7 günlük alım sonrası $>1$ olarak belirlenmiştir. Ayrıca çocuklarda 3 günlük tüketim neticesinde ise TTHQ'nun 1'e yakın olması nedeniyle dikkat edilmesi gerekmektedir. Yetişkinlerdeki As elementinin THQ değerinin (0.9051) tehlike limitine yakın olması, 7 günlük tüketim sonrası TTHQ değerinin $>1$ olduğunu göstermiştir. Dolayısıyla bu türün 7 günlük tüketimi hem yetişkinlerde hem de çocuklarda sakıncalı olabilmektedır. Storelli vd. (2012) mevcut çalışmamızda elde edilen sonuçlar gibi, kupez kas dokusunun THQ ve TTHQ değerlerinin 1'den daha düşük olduğunu bildirmişlerdir. Benzer şekilde, Agusa vd. (2005), ağır metallerin deniz ürünleri tüketimine göre sağlık risk tahminlerini ele alan, aynı zamanda günlük Cd ve Cu alımının USA EPA (2019) sınırlarını aşmadı̆̆ını da belgelemiştir.

A. queketti kas dokusunun tüketimi ile olası kanser riski açısından $\mathrm{Cr}$, $\mathrm{As}, \mathrm{Cd}$ ve $\mathrm{Pb}$ için $\mathrm{CRi}$ değerleri hesaplanmıştır. Sağlıklı bir insanın kansere yakalanma olasılığı $10^{-5}$ 'tir ve CRi değerinin bu eşiğin altında olması beklenir. Mevcut çalışmada CRi ve $\mathrm{CRi}_{\mathrm{Cr}}$ her iki tüketici grubunda $\leq 10^{-5}$ olarak hesaplanmış, $\mathrm{Pb}$ ve $\mathrm{Cr}$ elemetinin tüketiciler için kanserojen risk düzeylerinin düşük olduğu belirlenmiştir. $\mathrm{CRi}_{\mathrm{Cd}}$ değeri 3 ve 7 günlük alımlarda çocuklar için riskli olurken yetişkinler için 7 günlük alım sonucu risk oluşturmaktadır. $\mathrm{CRi}_{\mathrm{As}}$ değerleri ise yetişkinlerde 1 günlük alım sonrası risk oluşturmazken diğer tüm alım günlerinde her iki grup için risk oluşturduğunu göstermiştir. Traina vd. (2019), iAs için hesaplanan CRi değerlerinin, kırmızı kefal dışındaki dokuz balık türü için belirlenen limit değerden düşük olduğunu ve As için CRi değerlerinin inceledikleri bazı türlerin aşırı tüketilmesi ile sağlık sorunlarına neden olabileceğini bildirmişlerdir. 
European Journal of Science and Technology

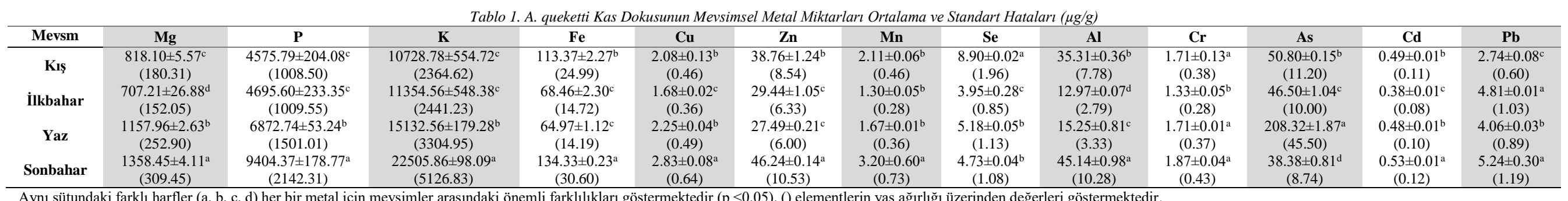

Aynı sütundaki farklı harfler (a, b, c, d) her bir metal için mevsimler arasındaki önemli farklılıkları göstermektedir ( $<<0.05)$. () elementlerin yaş ağırlığı üzerinden değerleri göstermektedir.

Tablo 2. Haftalk Tahmini Tüketim (EWI; $\mu \mathrm{g} / \mathrm{kg} B W$ )

\begin{tabular}{|c|c|c|c|c|c|c|c|c|c|c|c|c|c|c|c|c|c|c|c|c|c|}
\hline & \multirow[b]{2}{*}{$\begin{array}{l}\text { Maruz kalma süresi } \\
\text { (gün/hafta) }\end{array}$} & \multicolumn{2}{|c|}{$\mathrm{Fe}$} & \multicolumn{2}{|c|}{$\mathrm{Cu}$} & \multicolumn{2}{|c|}{$\mathbf{Z n}$} & \multicolumn{2}{|c|}{ Mn } & \multicolumn{2}{|c|}{ Se } & \multicolumn{2}{|c|}{ Al } & \multicolumn{2}{|c|}{$\mathrm{Cr}$} & \multicolumn{2}{|c|}{ iAs } & \multicolumn{2}{|c|}{ Cd } & \multicolumn{2}{|c|}{$\mathbf{P b}$} \\
\hline & & $\underline{\mathbf{Y}}$ & C & $\underline{\mathbf{Y}}$ & C & $\underline{\mathbf{Y}}$ & C & $\underline{\mathbf{Y}}$ & C & $\underline{\mathbf{Y}}$ & C & $\underline{\mathbf{Y}}$ & C & $\underline{\mathbf{Y}}$ & C & $\underline{\mathbf{Y}}$ & C & $\underline{\mathbf{Y}}$ & C & $\underline{\mathbf{Y}}$ & C \\
\hline \multirow{3}{*}{ EWI } & 7 & 376.23 & 822.99 & 2380.61 & 2.14 & 13.84 & 30.26 & 1.05 & 2.29 & 2.37 & 5.19 & 9.50 & 20.77 & 0.73 & 1.61 & 1.01 & 2.22 & 0.20 & 0.44 & 1.06 & 2.31 \\
\hline & 3 & 161.24 & 352.71 & 1020.26 & 0.92 & 5.93 & 12.97 & 0.45 & 0.98 & 1.02 & 2.23 & 4.07 & 8.90 & 0.31 & 0.69 & 0.43 & 0.95 & 0.09 & 0.19 & 0.45 & 0.99 \\
\hline & 1 & 53.75 & 117.57 & 340.09 & 0.31 & 1.98 & 4.32 & 0.15 & 0.33 & 0.34 & 0.74 & 1.36 & 2.97 & 0.10 & 0.23 & 0.14 & 0.32 & 0.03 & 0.06 & 0.15 & 0.33 \\
\hline
\end{tabular}

Y: Yetişkin ve Ç: Çocuk

Tablo 3. Hedef Tehlike Oranı (THQ) ve Toplam Hedef Tehlike Oranı (TTHQ)

\begin{tabular}{|c|c|c|c|c|c|c|c|c|c|c|c|c|c|c|c|c|c|c|c|c|c|c|c|}
\hline & \multirow[b]{2}{*}{$\begin{array}{c}\text { Maruz kalma } \\
\text { süresi } \\
\text { (gün/hafta) }\end{array}$} & \multicolumn{2}{|c|}{$\mathrm{Fe}$} & \multicolumn{2}{|c|}{$\mathbf{C u}$} & \multicolumn{2}{|c|}{$\mathbf{Z n}$} & \multicolumn{2}{|c|}{ Mn } & \multicolumn{2}{|c|}{ Se } & \multicolumn{2}{|c|}{ Al } & \multicolumn{2}{|c|}{$\mathrm{Cr}$} & \multicolumn{2}{|c|}{ iAs } & \multicolumn{2}{|c|}{ Cd } & \multicolumn{2}{|c|}{$\mathbf{P b}$} & \multicolumn{2}{|c|}{ TTHQ } \\
\hline & & $\underline{\mathbf{Y}}$ & C & $\underline{\mathbf{Y}}$ & C & $\underline{\mathbf{Y}}$ & C & $\underline{\mathbf{Y}}$ & C & $\underline{\mathbf{Y}}$ & C & $\underline{\mathbf{Y}}$ & C & $\underline{Y}$ & C & $\underline{\mathbf{Y}}$ & C & $\underline{\mathbf{Y}}$ & C & $\underline{\mathbf{Y}}$ & C & $\underline{\mathbf{Y}}$ & $\underline{C}$ \\
\hline \multirow{3}{*}{ THQ } & 7 & 0.0073 & 0.0159 & 0.0029 & 0.0064 & 0.0063 & 0.0007 & 0.0008 & 0.0017 & 0.0520 & 0.0054 & 0.0015 & 0.0032 & 0.0292 & 0.0640 & 0.9051 & 1.9799 & 0.0248 & 0.0543 & 0.0558 & 0.1221 & 1.09 & 2.25 \\
\hline & 3 & 0.0031 & 0.0068 & 0.0013 & 0.0027 & 0.0027 & 0.0003 & 0.0003 & 0.0007 & 0.0222 & 0.0023 & 0.0006 & 0.0014 & 0.0125 & 0.0273 & 0.3868 & 0.8462 & 0.0106 & 0.0232 & 0.0239 & 0.0522 & 0.46 & 0.96 \\
\hline & 1 & 0.0010 & 0.0023 & 0.0004 & 0.0009 & 0.0009 & 0.0001 & 0.0001 & 0.0002 & 0.0074 & 0.0008 & 0.0002 & 0.0005 & 0.0042 & 0.0091 & 0.1289 & 0.2821 & 0.0035 & 0.0077 & 0.0080 & 0.0174 & 0.15 & 0.32 \\
\hline
\end{tabular}

Y: Yetişkin ve C.: Cocuk; THQ değerleri > 1 koyu olarak gösterilmistir.

Tablo 4. Yașam Boyu Kanser Riski (CRi)

\begin{tabular}{|c|c|c|c|c|c|c|c|c|c|}
\hline & \multirow[b]{2}{*}{$\begin{array}{l}\text { Maruz kalma süresi } \\
\text { (gün/hafta) }\end{array}$} & \multicolumn{2}{|c|}{ CRicr } & \multicolumn{2}{|c|}{$C R i_{A s}$} & \multicolumn{2}{|c|}{$C R i_{C d}$} & \multicolumn{2}{|c|}{ CRipb } \\
\hline & & $\underline{\mathbf{Y}}$ & C & $\underline{\mathbf{Y}}$ & C & $\underline{\mathbf{Y}}$ & C & $\underline{\mathbf{Y}}$ & C \\
\hline \multirow{3}{*}{ CRi } & 7 & $4.39 \mathrm{E}-05$ & $9.59 \mathrm{E}-05$ & 4.07E-04 & 8.91E-04 & $1.56 \mathrm{E}-04$ & $1.56 \mathrm{E}-03$ & $1.90 \mathrm{E}-06$ & $4.15 \mathrm{E}-06$ \\
\hline & 3 & 1.87E-05 & 4.10E-05 & $1.74 \mathrm{E}-04$ & 3.81E-04 & $6.68 \mathrm{E}-05$ & $1.46 \mathrm{E}-04$ & $8.11 \mathrm{E}-07$ & $1.77 \mathrm{E}-06$ \\
\hline & 1 & $6.25 \mathrm{E}-06$ & $1.37 \mathrm{E}-05$ & $5.80 \mathrm{E}-05$ & $1.27 \mathrm{E}-04$ & $2.23 \mathrm{E}-05$ & $4.87 \mathrm{E}-05$ & $2.70 \mathrm{E}-07$ & $5.92 \mathrm{E}-07$ \\
\hline
\end{tabular}




\section{Sonuç}

Mevcut çalışmanın sonuçları, Kuzeydoğu Akdeniz'den yakalanan A. queketti türünün metal içeriklerinin insan tüketimi açısından risk değerlendirmesini ortaya koymaktadır. Bulgular metal dağılımı açısından araştırılan balık türünün iyi bir besinsel kaynak olduğunu göstermiştir. Hem yetişkinler hem de çocuklar için hesaplanan kanserojen olmayan değerleri genel olarak bu türlerin tüketiminden kaynaklanan önemli bir tehlike bulunmadığını göstermiştir. Ancak yoğun tüketim durumunda, kanserojen açıdan Cd ve As için olası risk oluşturabileceğini göstermiştir. Bununla birlikte, bu türün besinsel özellikleri ile ilgili daha fazla araştırma yapılması önerilmektedir.

\section{Kaynakça}

Akyol, O., \& Unal, V. (2015). Short communication Additional record of the Lessepsian Apogon queketti Gilchrist, 1903 (Osteichthyes: Apogonidae) from the Aegean Sea (Gokova Bay, Turkey). Journal of Applied Ichthyology, $1,2$.

Andaloro, F., Romeo, T., Renzi, M., Guerranti, C., Perra, G., Consoli, P., Perzia, P., \& Focardi, S. E. (2012). Alteration of potential harmful elements levels in sediments and biota from the central Mediterranean Sea (Aeolian Archipelago) following an episode of intense volcanic activity. Environmental Monitoring and Assessment, 184(7), 4035-4047.

ATSDR (Agency for Toxic Substance and Disease Rigestry). (2017). Priority list of hazardous substances. Atlanta, Georgia, USA.

Brown, M. T., \& Depledge, M. H. (1998). Determinants of trace metal concentrations in marine organisms. In Metal metabolism in aquatic environments (pp. 185-217). Springer, Boston, MA.

Canli, M., \& Atli, G. (2003). The relationships between heavy metal (Cd, Cr, Cu, Fe, Pb, Zn) levels and the size of six Mediterranean fish species. Environmental pollution, 121(1). 129-136.

Copat, C., Arena, G., Fiore, M., Ledda, C., Fallico, R., Sciacca, S., \& Ferrante, M. (2013). Heavy metals concentrations in fish and shellfish from eastern Mediterranean Sea: consumption advisories. Food and Chemical Toxicology, 53, 33-37.

EFSA Panel on Contaminants in the Food Chain (CONTAM). (2009). Scientific Opinion on arsenic in food. EFSA Journal, 7(10), 1351.

Ersoy, B., \& Çelik, M. (2010). The essential and toxic elements in tissues of six commercial demersal fish from Eastern Mediterranean Sea. Food and Chemical Toxicology, 48, 1377-1382.

Eryilmaz L. \& Dalyan C., (2006). First record of Apogon queketti Gilchrist (Osteichthyes: Apogonidae) in the Mediterranean Sea. Journal of Fish Biology, 69: 1251-1254, (EMEDTURLEV-L296)

FAO/WHO. (1983). Evaluation of certain food additives and contaminants: twenty-seventh report of the Joint FAO Expert Committee on Food Additives. WHO technical report series no. 983. Geneva, Italy

Froese, R., \& Pauly, D. (2014). Fishbase. World Wide Web electronic publication. Available at: www.fishbase.org. Version (02/2014) (accessed on 22 April 2014).

Golani, D., Orsi-Relini, L., Massuti, E., \& Quignard, J. P. (2002). CIESM Atlas of exotic species in the Mediterranean, Vol. 1. Fishes. 256 pp. Available at: www.ciesm.org/online/atlas/ (accessed on 22 April 2014).

Ikem, A., \& Egiebor, N. O. (2005). Assessment of trace elements in canned fishes (mackerel, tuna, salmon, sardines and herrings) marketed in Georgia and Alabama (United States of America). Journal of Food Composition and Analysis, 18, $771-787$.

JECFA (2011). Evaluation of certain food additives and contaminants: Seventyfourth report of the Joint FAO/WHO Expert Committee on Food Additives. WHO technical report series no. 966. Rome, Italy

JECFA (2013). Evaluation of certain food additives and contaminants: Seventyfourth report of the Joint FAO/WHO Expert Committee on Food Additives. WHO technical report series no. 983. Rome, Italy

Korkmaz, C., Ay, Ö., Ersoysal, Y., Köroğlu, M. A., \& Erdem, C. (2019). Heavy metal levels in muscle tissues of some fish species caught from north-east Mediterranean: Evaluation of their effects on human health. Journal of Food Composition and Analysis, 81, 1-9.

Kulcu, A. M., Ayas, D., Kosker, A. R., \& Yatkin, K. (2014). The Investigation of metal and mineral levels of some marine species from the Northeastern Mediterranean Sea. Journal of Marine Biology \& Oceanography, 3, 2, 2.

Monikh, F. A., Safahieh, A., Savari, A., \& Doraghi, A. (2013). Heavy metal concentration in sediment, benthic, benthopelagic, and pelagic fish species from Musa Estuary (Persian Gulf). Environmental Monitoring and Assessment, 185(1), $215-222$.

Smith, J. L. B. (1965). The Sea fishes of Southern Africa, 5th edn. Central News Agency Ltd., South Africa. 580 pp.

Traina, A., Bono, G., Bonsignore, M., Falco, F., Giuga, M., Quinci, E. M., ... \& Sprovieri, M. (2019). Heavy metals concentrations in some commercially key species from Sicilian coasts (Mediterranean Sea): Potential human health risk estimation. Ecotoxicology and Environmental Safety, 168, 466-478.

US EPA (U.S. Environmental Protection Agency). (2019). Regional screening levels (RSLs) - equations. https://www.epa.gov/risk/regional-screening-levels-rsls-equations

US EPA (United States Environmental Protection Agency), 2008. Child-Specific Exposure Factors Handbook (Final Report) 2008. EPA/600/R-06/096F. National Center for Environmental Assessment Office of Research and Development, Washington, DC.

US EPA (US Environmental Protection Agency). (2000). Guidance for Assessing Chemical Contaminant Data for Use in Fish Advisories, Volume II. Risk Assessment and Fish Consumption Limits. EPA 823-B-00-008. United States Environmental Protection Agency, Washington, DC. 
US EPA. (2014). United States Environmental Protection Agency. Mid- Atlantic Risk Assessment. United States Environmental Protection Agency, Washington, URL:〈http://www.epa.gov/reg3hwmd/risk/human/rb-oncentration_table/users- guide. htm> (Accessed 26.03.14).

Yılmaz, A.B. (2005). Comparison of heavy metal levels of grey mullet (Mugil cephalus L.) and sea bream (Sparus aurata L.) caught in Iskenderun Bay (Turkey). Turkish Journal of Veterinary and Animal Sciences, 29, 257-262. 